\title{
Percutaneous lumbar discectomy with a working endoscope and laser assistance
}

\section{Martin H. Savitz, M.D., Howard Doughty, R.N., and Paul Burns, M.D.}

Division of Neurosurgery, Department of Surgery, Community Hospital, Dobbs Ferry, New York; Division of Neurosurgery, Department of Surgery, Nyack Hospital, Nyack, New York; and Department of Anesthesia, Good Samaritan Hospital, Suffern, New York

The authors describe percutaneous disc surgery performed via the unilateral monoportal method with a $\mathrm{C}$-arm image intensifier, a working endoscope, and an yttrium-aluminum-garnet laser in 300 patients at three community hospitals over a 6-year period. Visualizing the area of the annulus to be fenestrated, verifying the status of the nerve root, inspecting the cavity created, and monitoring laser hemostasis and vaporization all contributed to patient safety. Fewer than $2 \%$ of the cases required a second surgery. The only postoperative sequelae recorded were one psoas hematoma, which resolved, and sympathetic mediated pain in 5\% of the patients who responded to appropriate treatment. For treatment of a prolapsed lumbar disc, a 1-hour endoscopic procedure performed while the patient receives a neuroleptanalgesic continues to be a significant surgical alternative.

Key Words * arthroscopic microdiscectomy * fluoroscopy * laser * percutaneous discectomy * endoscopy

After training with Parviz Kambin, one author in suburban practice reported a series of 120 same-day, microsurgical, arthroscopic, lateral-approach, laser-assisted fluoroscopic discectomies performed in 100 patients over a 2-year period.[8] Other percutaneous methods for lumbar discectomy in the neurosurgical and orthopedic literature include medial nucleotomy by an automated probe,[7] biportal arthroscopic microdiscectomy,[4] and disc vaporization by a fluoroscopically placed laser fiber.[10] Using a unilateral, monoportal, endoscopic method, we achieved partial resection of 340 herniated lumbar discs in 300 patients over a 6-year period.

\section{CLINICAL MATERIAL AND METHODS}

The basic materials consisting of Kambin's orthopedic instruments and frame for arthroscopic microdiscectomy and a working endoscope have remained unchanged since the initial report.[8] In 1996, the neodymium:yttrium-aluminum-garnet (Nd:YAG) laser, which had been confined to use in hemostasis, was replaced by the holmium:yttrium-aluminum-garnet (Ho:YAG) laser (New Star Lasers, Inc., Auburn, CA), which was approved by the Food and Drug Administration for disc vaporization. A portable unit allowed us to schedule the procedure at three community hospitals in two suburban counties 
within a 25-mile radius of New York City.

There were 300 patients in the series (168 men and 132 women) with age ranging from 16 to 81 years. The diagnoses were made by computerized tomography, magnetic resonance imaging, and/or myelography; half of the patients had undergone two neuroradiological studies. No disc was extruded, but the contained prolapses occupied up to $50 \%$ of the spinal canal in 279 patients (Fig. 1 left). Twelve patients presented with an extremely lateral disc herniation (Fig. 1 right).
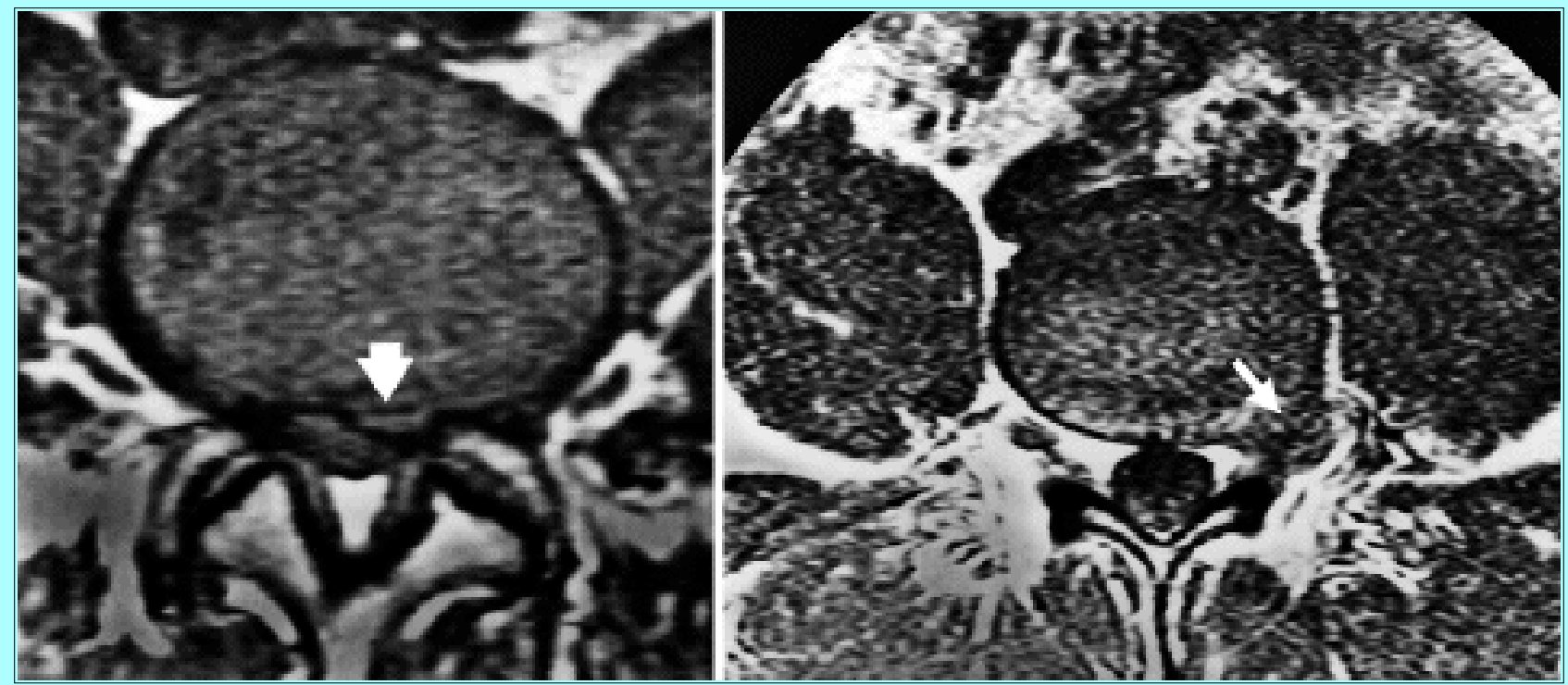

Fig. 1. Left: Magnetic resonance image demonstrating disc herniation (arrow) into left lateral recess. Right: Magnetic resonance image showing left foraminal herniated disc (arrow) compressing the exiting nerve root.

Nine patients older than 65 years of age, with a diagnosis of a soft herniated nucleus pulposus in the presence of a narrow canal (Fig. 2), were included in a prior report on lumbar stenosis.[9] All of our patients had been symptomatic with sciatica for at least 6 months. Two hundred sixty patients had a single herniated nucleus pulposus, and 40 had two disc herniations (Table 1). During the same period between March 1991 and August 1997, specimens from four other patients with disc space infections were cultured and biopsy specimens were obtained in three spinal tumors. 


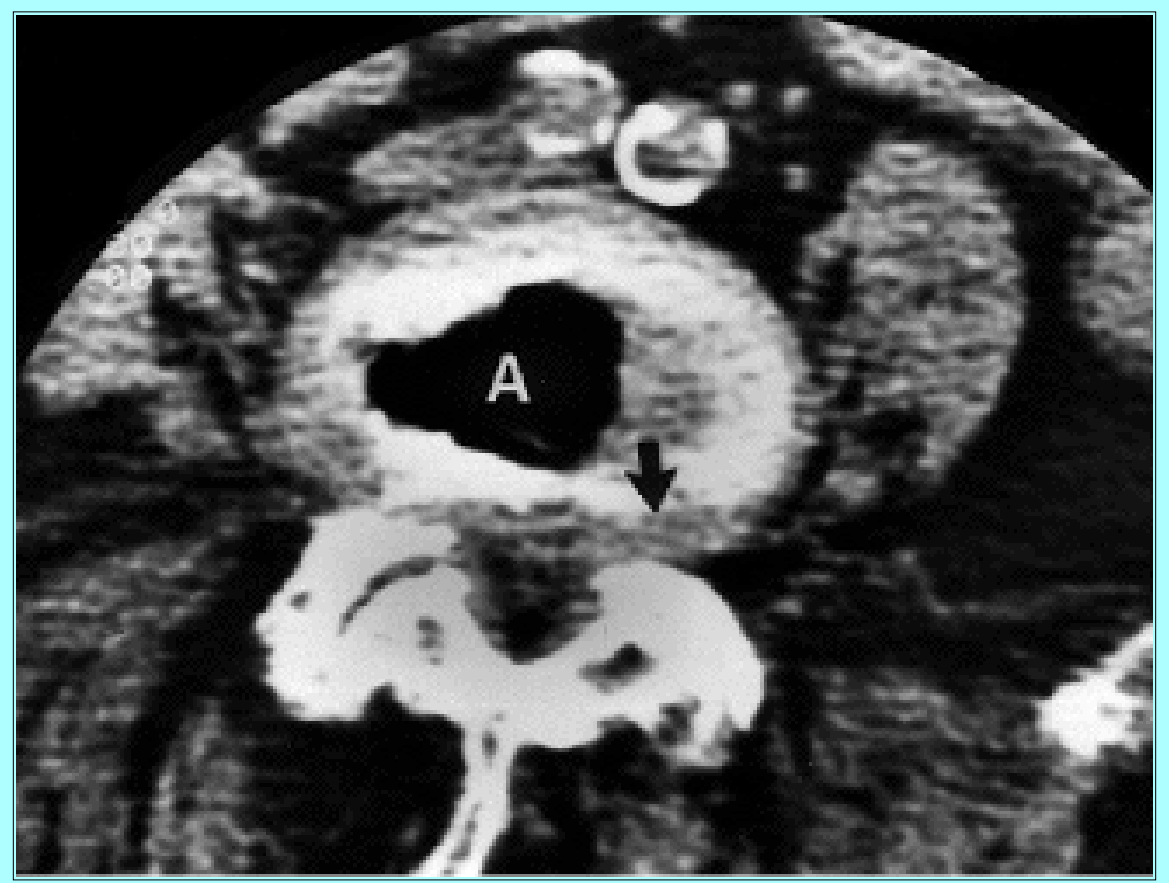

Fig. 2. Computerized tomography scan showing air (A) consistent with degenerative disc disease as well as soft herniation (arrow). Note superimposed facet hypertrophy causing stenosis.

\begin{tabular}{|c|c|}
\hline \multicolumn{2}{|c|}{$\begin{array}{c}\text { TABLE } 1 \\
\text { LOCATION OF HERNIATED NUCLEUS PULPOSUS IN } 300 \text { PATIENTS } \\
\text { UNDERGONG PERCUTANEOUS LUMBAR DISCECTOMY } \\
\end{array}$} \\
\hline Location & No. of Cases \\
\hline $\begin{array}{l}1 \text { le vel } \\
\text { L2-3 } \\
\text { L3-4 } \\
\text { L4-5 } \\
\text { L5-S1 } \\
2 \text { levels } \\
\text { L2-3 \& L4-5 } \\
\text { L3-4 \& L4-5 } \\
\text { L4-5 \& L5-S1 }\end{array}$ & $\begin{array}{r}4 \\
11 \\
146 \\
99\end{array}$ \\
\hline
\end{tabular}

The skin and annular entry sites, radiographically identified triangular working zone, and the use of neuroleptanalgesic agents have been described.[8] We alternated fluoroscopic viewing of instrument placement and location with direct visualization provided by the working endoscope. The forceps that removed disc material (Fig. 3 left) and the laser fiber that produced hemostasis and vaporization (Figs. 3 center and right) could be followed on the television monitor. Settings used for the Ho:YAG laser were 5 to $10 \mathrm{pulses} / \mathrm{second}$ and continuous; the built-in audio feedback provided additional control of increasing wattage. The vaporization heat was limited to the disc space by constant irrigation with saline. The regimen of systemic cefazolin and topical bacitracin and polymyxin was continued, and each patient received $10 \mathrm{mg}$ of intravenous dexamethasone prior to discharge. 

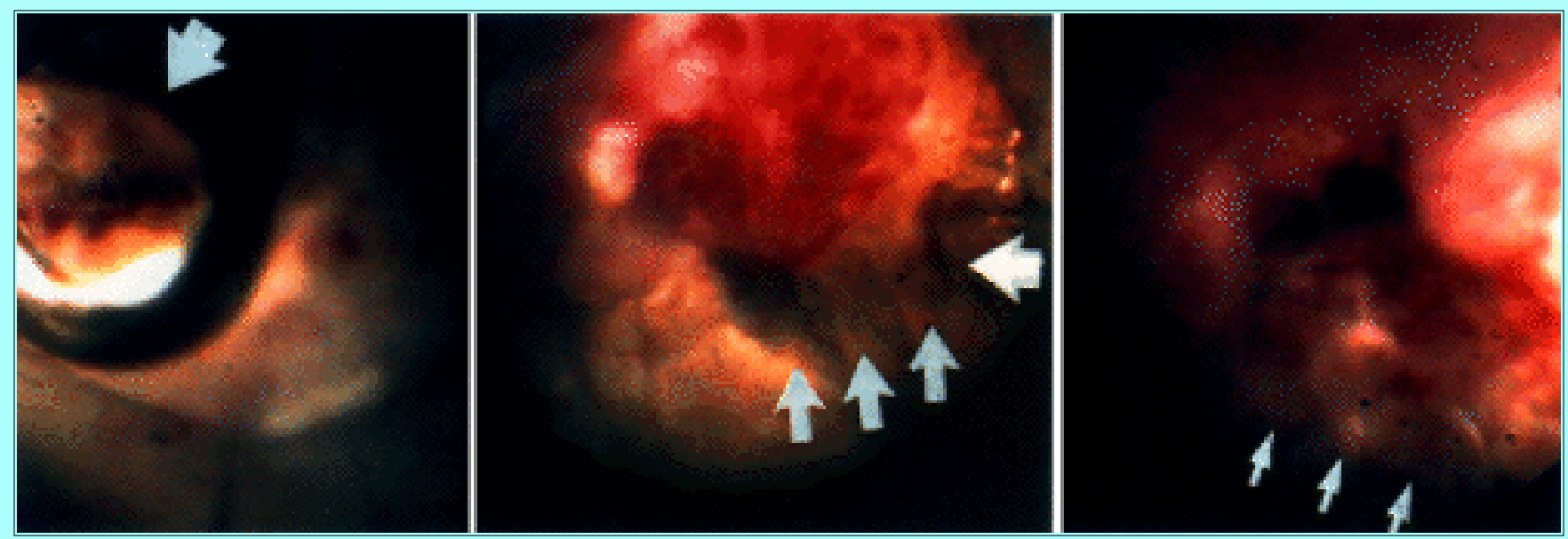

Fig. 3. Left: Intraoperative photograph showing an arthroscopic view of the head of flexible forceps (arrow) removing disc material after coring. Center: View of laser fiber (large arrow) producing areas of localized hemostasis (small arrows) on the edge of the cavity behind the annulus. Right: View of bubbles and debris (arrows) emanating from cavity as laser wattage is increased to vaporize disc material.

\section{RESULTS}

Success was judged in part by patient satisfaction; complete success was evidenced in two-thirds of the cases (Table 2) by early return to work. Improvement was also determined by resumption of employment within 6 months or by increased mobility and a reduction in pain medication from narcotic to analgesic agents. Four patients underwent reexploration via laminotomy but only two improved; no retained fragments were found, but foraminal stenosis that had not been visualized on preoperative neuroradiological studies was present. The 12 patients with an extremely lateral disc herniation recovered from neuroleptanalgesia free of pain. Eight of the nine patients with a soft herniated nucleus pulposus in the presence of spinal stenosis had excellent relief of sciatica; one patient required subsequent decompressive laminectomy after developing neurogenic claudication. There was one incident of psoas hematoma in the first 100 patients,[8] evidenced by pain radiating to the groin and weakness in the proximal musculature of the thigh; the patient improved after receiving a 5-day course of steroids.

\begin{tabular}{|c|c|c|c|}
\hline \multicolumn{4}{|c|}{$\begin{array}{c}\text { TABLE } 2 \\
\text { OUTCOME IN } 300 \text { PATIENTS WHO UNDERWENT PERCUTANEOUS } \\
\text { LUMBAR DISCECTOMY } \\
\end{array}$} \\
\hline \multirow[b]{2}{*}{ Outcome } & \multicolumn{3}{|c|}{ No. of Patierts } \\
\hline & $\begin{array}{l}\text { Certral } \\
\text { Prolapse }\end{array}$ & $\begin{array}{c}\text { Lateral } \\
\text { Hemiation }\end{array}$ & $\begin{array}{l}\text { Stenosis } \\
\text { \& } \mathrm{HNF}^{*}\end{array}$ \\
\hline returned to work & $186(67 \%)$ & $8(67 \%)$ & \\
\hline $\begin{array}{l}\text { reduced medication } \\
\text { reop, not im pro ved }\end{array}$ & $\frac{90}{1}(32 \%)$ & $\begin{array}{l}3(25 \%) \\
1\end{array}$ & $8(89 \%)$ \\
\hline reop, im proved & 2 & & 1 \\
\hline total cases & 279 & 12 & 9 \\
\hline
\end{tabular}

Fifteen patients developed sympathetic mediated pain (SMP)[3] within 7 days after discharge. Whereas classic signs of causalgia or reflex sympathetic dystrophy (trophic skin changes, soft-tissue swelling, vasomotor disturbances, and joint immobilization) were absent, all of these patients complained of 
varying degrees of burning sensations, hyperalgesia, and distal swelling of the lower extremity. Initial treatment consisted of oral Hytrin and Elavil. Intravenous infusion of phentolamine eliminated the pain and confirmed the diagnosis in 12 patients. Placement of lumbar sympathetic blocks over a 6- to 10-week period were effective in controlling the symptoms with adjustment of the oral regimen of medications. The symptoms of SMP resolved in three cases after administration of nonsteroidal antiinflammatory drugs alone.

\section{DISCUSSION}

Percutaneous discectomy using an automated probe[7] and laser nucleolysis[2,10] are performed without benefit of fiberoptic visualization and involve an attempted decompression by limited medial nucleotomy. Biportal arthroscopic microdiscectomy[4] entails annulectomy and removal of disc material from the unaffected side to allow extensive exploration of the intervertebral space. Percutaneous endoscopic discectomy, however, requires only a unilateral, monoportal approach and involves posterior quadrantectomy under direct monitoring of instrumentation, aspiration, and laser vaporization and hemostasis. Kambin and coworkers[5] more recently reported transforaminal arthroscopic decompression of lateral recess stenosis by microdiscectomy, resection of osteophytes, and removal of sequestered fragments. Despite their use of a specially designed radiofrequency coagulator to control epidural bleeding, a 4-mm Hemovac drain was regularly needed to prevent hematoma formation.

The use of the Nd:YAG laser was confined to use in hemostasis in the first 200 patients; settings of 17 to $21 \mathrm{~W}$ and 1.5 -second pulses were used, but charring took place suddenly and without predictability as the wattage was increased.[8] Using only fluoroscopic guidance, damage to the annulus and posterior longitudinal ligament has been reported when disc vaporization was attempted with the Nd:YAG laser.[1,6] The Ho:YAG laser, however, provides more limited areas of hemostasis and charring (Fig. 5) and has the added safety feature of audio feedback coupled with video monitoring as vaporization takes place (Fig. 6). Without the insertion of drains, only one complication of psoas hematoma was recorded in our entire series of 340 discectomies in 300 patients.

Sympathetic mediated pain may occur with any injury or surgical manipulation of a peripheral nerve. Kambin and coworkers[5] recorded delayed postoperative causalgic-type pain in four (10\%) of 40 of their patients who subsequently responded to administration of steroids or nonsteroidal antiinflammatory drugs; transforaminal decompression involved trephination of calcified annular fibers and bone spurs as well as direct contact with the traversing nerve root. In our series, the administration of alpha blockers and the performance of sympathetic blocks were required in 12 of the 15 patients who developed SMP despite our practice of avoiding exposure or direct manipulation of the nerve root. The mechanism and cause of SMP in patients undergoing percutaneous endoscopic discectomy remain unidentified and poorly understood.

\section{CONCLUSIONS}

Used in combination, Kambin's instruments with the addition of a working endoscope, C-arm image intensifier, and a portable Ho:YAG laser allow alternating fluoroscopic and fiberoptic monitoring of trephine coring, forceps evacuation, and laser vaporization and hemostasis. Surveying the area of the annulus to be fenestrated, verifying the status of the nerve root, inspecting the cavity created, and observing laser hemostasis and vaporization all contribute to the safety of endoscopic lumbar discectomy. The infrequent complications recorded have required outpatient therapy rather than prolonged hospitalization, and the rate of second surgery has been less than $2 \%$. For the treatment of a 
prolapsed lumbar disc, a 1-hour percutaneous procedure performed while the patient is receiving a neuroleptanalgesic continues to be a significant surgical alternative.

\section{References}

1. Choy DSJ: Risks of laser discolysis. J Neurosurg 77:978, 1992 (Letter)

2. Choy DSJ, Case RB, Fielding W, et al: Percutaneous laser nucleolysis of lumbar disks. N Engl J Med 317:771-772, 1987

3. Hendler N, Raja SN: Reflex sympathetic dystrophy and causalgia, in Tollison CD, Satterthwaite JR, Tollison, JW (eds), Handbook of Pain Management. Baltimore: Williams \& Wilkins, 1994, pp 484-496

4. Kambin P: Arthroscopic microdiscectomy. Arthroscopy 8:287-295, 1992

5. Kambin P, Casey K, O'Brien E, et al: Transforaminal arthroscopic decompression of lateral recess stenosis. J Neurosurg 84:462-467, 1996

6. Lavyne MH: Complications of percutaneous laser nucleolysis. J Neurosurg 76:1041, 1992 (Letter)

7. Onik G, Mooney V, Maroon JC, et al: Automated percutaneous discectomy: a prospective multi-institutional study. Neurosurgery 26:228-232, 1990

8. Savitz MH: Same-day microsurgical arthroscopic lateral-approach laser-assisted (SMALL) fluoroscopic discectomy. J Neurosurg 80:1039-1045, 1994

9. Savitz MH: Soft disc herniation in patients with lumbar stenosis. Neurosurg Focus 3 (2):Article 7, 1997

10. Siebert WE, Berendsen BT, Tollgaard J: [Percutaneous laser disk decompression. Experience since 1989.] Orthopade 25:42-48, 1996 (Ger)

Manuscript received January 14, 1998.

Accepted in final form January 23, 1998.

Address reprint requests to: Martin H. Savitz, M.D., 55 Old Turnpike Road, Suite 101, Nanuet, New York 10956. 